larua is hatched. Before this occurs, small processes, each of which is the radiment of an external gill, grow, in most forms, from the outer side of the first and second branchial arches. A similar rudiment is found before or after hatching on the third arch, but none is present on the fourth. These external gills soon elongate, and form branched ciliated processes floating freely in the medium round the embryo. They differ essentially from the gills of Elasmobranchs in being covered with epiblast. The period of hatching varies in different larva, but in most cases, when it oocurs, the mouth has not yet become perforated. The larva, or tadpole, is at first enclosed in the detritus of the gelatinous egg coverings. The tail very soon becomes a powerful swimming organ, by the devolopment of a dorsal and ventral fin. Before the larva begins to feed, growth is donbtless carried on at the expense of the yolk. which at this time is enclosed in the mesenteron. The mouth and anal perforations soon make their nppearance, and the animal is then able to feed. The gill-slits also become perforated, but the hyomandibular divcrtioulum, in most species, never actually opens externally, and in all cases very soon becomes closed.

Shortly after hatching, an opercular fold of skin grows ont from the hyoid arch on each side, which gradually covers over the posterior branchial arches and the external gills. It fuses with the skin at the upper part of the gill-arcles, and also with that of the pericardial wall below them, but is free in the middle, and 80 assists in forming what is called the branchial cavity, in which the gills are placed. Each branchial cavity at first opens by a somewhat wide pore behind, and in Dactylethra both branchial apertures are preserved. In the larva of some forms, as Bombinator, the original openings of the two branchial chambers meet together in the ventral line, and form a single branchial opening. In most other forms, as in Bufo, Rana, etc., the two branchial chambers become united by a transverse canal, and the opening of the right sac then disappears, while that of the left remains as the single unsymmetrical spiracle. In breathing, the water is taken in at the mouth, and passes through the branchial cavities, from which it is carried out by the spiracle.

Immediately after the formation of branchial cavities, the original external gills atrophy, but in their place fresh gills, usually called internal gills, appear on the outcr side of the middle region of the four branchial arches. There is a single row of these on the first and fourth branchial arches, and two rows on the second and third. In addition to these gills, branched processes appear on the hypoblastic walls of the three branchial clefts. These processes seem to be homologous with the gills of the lamprey. In Dactylethra, no other gills but these are found.

The mouth acquires a transversely oval form even before the tad. pole begins to feed, and becomes armell with provisional structures in the form of a horny beak and teeth, which are in use during larval life. As the animal acquires its full development, the suctorial organs behind the mouth atrophy gradually. The alimentary canal, which is at first short, rapidly elongates and fills up the large body-cavity with its numerous coils. In the meantime, the lungs develop as outgrowths from the cesophagus.

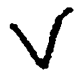

\section{RUPTURE OF BLADDER.}

\section{BY J. B. HAMILTON, M.D., Surgeon-Major,} Station Hospital, Portobello, Dublin.

DRIVER M., Royal Horse Artillery, was brought to hospital on the morning of Mny 4th, with the following history.

He had been in the habit of drinking pretty freely (though not artually an intemperate man) large quantities of porter. He had for some time previonsly been quartered in a room on the ground. floor, and had been seen frequently to get out of the window dnring the night, dropping about three feet to the ground, to visit the urinal. A few days previously to the abore datc, he had been removed to a room in barracks on the first-floor, the window-sill of which was about twenty feet from the ground.

On the evening of May 3rd, the man had been drinking in the canteen; and, according to his own admission, must have consumed about a gallon of porter, between the hours of 6 and 9.30 P.M. went to bed about 10 P.M.; and, a little after 1 A.M. on the 4th, an other man in the room heard the window being opened, and, looking up, saw driver M. sitting on the window-sill, with his legs outside before he could save him, he slipper off, in a sitting attitude, and fell twenty feet on the parement below.

The man was carried to hospital, and, on admission, was found to have no external injuries. He was put to bed, and, between that time and 10 A.X., he passed a considerable quantity of urine in bed under him, the sheets and mattress being wet.

At 10 A.M., I found him in the following condition. He was drowsy, evidently from the effects of drink; tongue dry. He com. plained of pain in the lower portion of the abdomen, and was unable to pass urine. I drew off with a No. 8 catheter about eight ounces of urine, mixed with rather bright blood. In the evening, his condition was much the same, and I again drew off about ten ounces of bloody urine.

Noxt day, he still complained of pain in the abdomen; and there was much tympanites, with constipation and sickness of stomach. The urine was again drawn off; the first few ounces being clear, the last portion tinged with dark blood. Fomentations were applied to the abdomen, and he was given ice to suck, and milk and soda-water in small quantities.

On the 6th (the third day), the urine was clear, a few dark clots coming just at the last. $\Lambda$ bout ten ounces were drawn off morning and evening. He complained of "colicky" pain" in the abdomen, but could bear pressure and percussion everywherc. The temperature was normal, the pulse fair, 120, the tongue moist; in fact, there were no urgent symptoms. Fomentations were kept to the abdomen, and enemata were giren with the long tube, bringing away much flatus and a small quantity of dark fæces. A grain of calomel with a quarter of a grain of opium was given every fourth hour. He had ice, milk, etc.

He continued in this condition till the evening of the 8th, and I last saw him alive at 6 P.M, that day. His condition was then apparently improved. He had passed urine twice naturally; his tongue was moist and clean; his temperature had fallen to $97^{\circ}$. The dis. tension of the abdomen was less. He had no motion from the borrels. The catheter was not introluced on this occasion, as it was not considered necessary; but, as his pulse was rather weak, he was given a small quantity of brandy at intervals.

At 5 A.M. on the 9th (five days and four hours after the fall), he suddenly grew faint, and died before I could be sent for.

$A$ coroner's inquest was held on Mlay 11th, and the following is the result of the post mortem examination, made fifty-six hours after death. The body was well nourished. Rigor mortis was complete. There was some post mortem lividity. No external injury could be detected, excepting a slight abrasion on the forchead. On opening the abdomen, a large quantity of dark-coloured fluid escaped, evidently urine, estimated at sixty ounces. The peritoneum was perfectly normal ; not a sign of peritonitis could be detected anywhere The intestines were distended with air. The diaphragm was intact. The liver, spleen, kidness, stomach, and intestines were all perfectly healthy. The bladder was found contracted in the pelvis, about the size of a hen's egg; and, on examination, there was found a rent in the anterior and upper portion, admitting the finger into the cavity.

The bladder was carefully remored, aul the rent examined. It was found to be fully an inch and three-quarters in length, trans. verse, and had torn all the coats, permitting the contents to escape into the peritoneal cavity.

REMARKs. - The points worthy of notice seem to be-1, the length of time (over five days) the man lived aiter the injury; 2, the total absence of peritonitis; 3 , the presence of sixty ounces of urine in the abdomen, though eiglit to ten ounces were drawn off morning and evening.

I can only imagine that the patient in falling alighted on his but. tocks, and, the bladder being distendel, ruptured from the slock, a species of contre coup; and that a considerable quantity of urine must have then escaped; the rent being kcpt partly closed by the distended intestines, there was only a partial leakage subsequently. The hemorrhage from the torn bladder accounts for the bloody urine and the subsequent clots. The trmpanites and irritability of stomach may be partly attributed to the injury, and also to the fact that the man bad eaten little or nothing for several days before admission, he having confessed to having swallowed little else than porter during the time.

The Contagtols Diseases Acts.-At a full chapter of the Guild of St. Luke, held recently, a paper strongly adrocating the repeal of the Contagious Diseases Acts was read; but, after an interesting discussion, the following resolution was carried unanimously, "That this meeting of the fuild of Saint Luke is strohgly in farour of the continuance, amendment, and extension of the Contagions Diseascs Act." 